\title{
REVIEW
}

\section{Emergency analgesia in the paediatric population. Part III Non-pharmacological measures of pain relief and anxiolysis}

\section{J J O'Donnell, S C Maurice, T F Beattie}

This paper discusses the benefits of non-pharmacological interventions for pain relief in children that can be used in the accident and emergency setting.

See end of article for authors' affiliations

Correspondence to Mr J J O'Donnell, Accident and Emergency

Department, University College Hospital, Newcastle Road, Galway, Ireland;

JohnJ.ODonnell@whb.ie
$\mathrm{P}$ ain is the commonest presenting complaint of patients who attend the accident and emergency (A\&E) department ${ }^{1}$ and is a complex sensation involving not only physical damage but also psychological, emotional, and behavioural factors. ${ }^{2}$ The psychological and emotional components of pain are particularly important in children, ${ }^{3}$ and the A\&E department can be a very stressful place for the child in pain. The relief of pain has been shown to be something that is generally poorly managed in A\&E, particularly in the paediatric A\&E population. ${ }^{4}$ In the first paper in this series we explored some of the reasons for this including poor communication between patient, parent and staff, inadequate pain recognition and assessment and poor understanding of analgesic drugs and techniques available for children. In this paper we will discuss the nonpharmacological measures that, when used in conjunction with drug therapies, act cumulatively to provide analgesia and anxiolysis to the child presenting to the A\&E department.

\section{THE A\&E ENVIRONMENT}

The A\&E department can be a very stressful place for children. Work with paediatric surgical patients identified five major stressors that children associated with hospitalisation. ${ }^{5}$ These were fear of separation from parents; fear of physical pain, mutilation and death; fear of the strange environment and procedures; fear of loss of control, autonomy and competence; and fear due to uncertainty about expected acceptable behaviour. Despite no comparable evidence for A\&E, we would postulate that these fears also exist in the A\&E setting. We can do much to alleviate these stressors by creating a reassuring environment aimed at children's needs. In their report on A\&E services for children, the Royal College of Paediatrics and Child Health make a number of recommendations about the facilities that should be available. ${ }^{6}$ Children should be seen in a designated paediatric area, which is audio-visually separate from the areas in which adults are treated. This should be designed to include a "child friendly" play area and have colourful wall murals and toys, books, equipment and play material available to provide a distraction for children that should be visible from the nurse's station. A dedicated play therapist is recommended for any A\&E department treating more than 18000 children per year ${ }^{6}$ and can be most useful in distracting the child from their pain with age appropriate toys and games, such as picture books, drawing and painting. Music and sound of all kinds are also useful methods of grasping a child's attention and sound books can be particularly useful in gaining a child's interest. ${ }^{7}$ Role playing such as pretending to stitch or auscultation of a toy can prepare a child for suturing or examination, ${ }^{8}$ and the National Association of Hospital Play Staff have published a number of leaflets that outline ideas on role playing and play focus for different conditions and environments within the hospital setting. Cartoon story books showing in picture form what happens when a child is admitted to hospital are also useful. There should be a range of toys available, including topical toys, material such as colouring books and crayons and equipment such as computer games, appropriate to the range of needs of children from babies, toddlers, preschool children, school age children, and adolescents and from different cultural backgrounds. The toys and equipment should meet the British Standards Institute (BS 5665) and European Community safety standards and must be regularly checked, regularly washed and replaced when needed by a member of staff designated to look after the toys or the play therapist. The play therapist can also supervise brothers and sisters of the child attending in the play area while the parent is in the consulting room and can minimise the risk of injury while playing and reduce the chance of toys getting broken or stolen.

Toys and books should also be available in the consulting and treatment rooms. Potentially frightening medical equipment and instruments should be hidden from sight or camouflaged where possible. The anxiety of being in a strange, new environment can be alleviated by arranging visits to the A\&E department by schoolchildren from the area. This allows them the chance to see around the department in non-threatening circumstances, to meet the staff, and to role play about what might happen if they need treatment.

Separation from parents has been shown to be a major cause of anxiety in children during painful procedures 9 and wherever possible at least one parent should be encouraged to stay with the child to reassure them in the A\&E department. It is most important to reassure and explain the 
procedure to the parent as a nervous parent will transfer their anxiety to the child. Parents however should not be bullied into staying with the child if they are anxious or squeamish.

If possible, seriously injured children should be allocated a dedicated liaison nurse. This nurse stays with the patient throughout their time in A\&E, explains what is happening and reassures the child and parent, but plays little part in the physical care of the child. This allows the child to form a bond with one person as their ally in the unfamiliar environment of $\mathrm{A} \& \mathrm{E}$, and is the most appropriate person to assess and monitor the child's pain.

\section{PSYCHOLOGICAL METHODS OF PAIN RELIEF}

Most psychological methods of pain relief are effective primarily as coping strategies, focusing the child's attention away from the pain on to something else. Various techniques are available including distraction, guided imagery, relaxation, hypnosis, and cognitive behavioural therapy. Many of these techniques can be used in the A\&E setting by medical and nursing staff. Before a procedure, preparatory age appropriate information about the procedure, including an explanation of what the child is likely to feel should increase the understanding of children and parents and reduce stress and anxiety ${ }^{10}$ During the procedure the child should be given verbal encouragement and sweeping statements such as "it won't hurt" should be avoided. ${ }^{11}$ Children may perceive their injury or illness as punishment for some disobedience and further pain in the A\&E department may reinforce this. Cooperative behaviour should be encouraged by praising the child rather than chastising them for not cooperating. The child should be permitted to make age appropriate choices to give a sense of control after a procedure has been explained to them. Allowing a child to bargain or stall often heightens the anxiety. ${ }^{12}$

Distraction is the most frequently used behavioural therapy and puts the pain at the "periphery of awareness". ${ }^{13}$ It seems best in helping the child to deal with relatively short duration pain such as procedural pain. ${ }^{14}$ Attention is focused on the distracter rather than the pain and to be effective the distraction must be interesting to the child, consistent with the child's energy level and ability to concentrate. It must stimulate the major sensory modalities—hearing, vision, touch, and movement-and be capable of providing a change in stimuli when the pain changes, for example, increasing stimuli as pain increases. Such distraction strategies must be appropriate for the age of the child such as: infant (up to 1 year)-music, cuddling, rocking using a soothing, quiet tone of voice. Preschool ( $1-5$ years ) - allow the child to have a sense of control by allowing the child to "help", for example, opening a dressing pack, holding a bandage. Singing, picture books, puppets and particularly stories are also very useful at this age. School age (6-12 years) - use creative imagery such as blowing an imaginary feather off the doctor's nose, playing with a kaleidoscope or 3D viewer or blowing bubbles. Adolescent-use a cassette player of their favourite music and encourage them to tap out or sing with it. Allow them to self create a scenario by asking "what would you rather be doing now?", etc.

Guided imagery involves the use of imagination to modify the response to pain. ${ }^{15}$ It can be used in a guided way so that the child imagines something about his or her pain that will help to reduce it. Children who have pain, for example, can picture the pain flowing out of their bodies or can imagine themselves in their favourite place or as their favourite character. It provides relaxation and distraction and produces an image of pain allowing the child to have some control of the situation. ${ }^{16}$ Relaxation reduces autonomic activity and as a patient cannot be relaxed and anxious simultaneously, pain tolerance should be increased if the patient is relaxed. A young child can be encouraged to relax simply by holding them in a comfortable well supported position or rocking them. Talking to a child in a soft, calm voice encourages relaxation. An older child can be encouraged to use deep breathing exercises by blowing bubbles, which can also be distracting.

Hypnosis has also been found to be useful in the management of patients with both acute and chronic pain ${ }^{11}$ and has been defined as focused attention, an altered state of consciousness or a trance, often accompanied by relaxation that decreases the child's perception of pain. There is evidence that hypnosis has been used in children for pain control from as early as $1840^{17}$ and in 1956 the benefits of the use of hypnosis in the "casualty" department for procedures such as fracture reduction and suturing were shown in both adult and paediatric patients. ${ }^{18}$ The vivid imaginations of children and the stressful experience of attending A\&E has been shown to heighten their susceptibility to hypnosis. ${ }^{19}$

Cognitive behaviour therapy entails desensitising the child to anxiety provoking stimuli and rewarding the child when they exhibit positive coping behaviour. To be effective, this therapy requires time and planning and thus its use is often limited in the A\&E setting.

\section{CUTANEOUS STIMULATION METHODS OF PAIN RELIEF}

Various methods of cutaneous stimulation or counter irritation methods can also be used to counteract the sensation of pain. These would include hot or cold application, superficial massage, acupuncture, and transcutaneous electrical nerve stimulation (TENS). Touch is a very effective way to communicate empathy and superficial massage of the soft tissues helps to produce relaxation of the muscles. Acupuncture is a system of ancient medicine that originated in China and is based on the idea that life force flows around certain lines on the body known as meridians, but has also been postulated to be related to the release of natural endorphins. ${ }^{20}$ The application of this may be limited as children are often afraid of needles. TENS delivers controlled low voltage electricity to the body via electrodes and has been found to be useful in the management of localised pain. It is thought to increase endorphin levels and act as a counter irritant, causing a tingling sensation when activated. ${ }^{16}$ It has been used with success in the management of chronic pain in children but may also have a role in the acute setting of the A\&E department.

\section{PHYSICAL METHODS OF PAIN RELIEF}

The use of splints or dressings can provide pain relief and should be applied as soon as possible, preferably in the prehospital setting, to the injured child. Splintage provides immobilisation of the affected limb and thus renders it less painful. ${ }^{21}$ Dressings can relieve both pain and anxiety. An example of this would be the application of a burns dressing, which soothes the affected area and also has the psychological benefit of covering the wound, the sight of which may be distressing to both child and parent.

\section{CONCLUSIONS}

Non-pharmacological methods of pain management are particularly important for children in pain who present to the stressful environment of the A\&E department. Many methods are available to us to complement the available drug therapies and A\&E staff should be aware of their importance in the management of paediatric pain. There is much potential for further research in this area in the A\&E setting.

\section{Contributors}

JJO'D undertook the initial literature review and completed the first draft of the paper. SCM contributed to the literature review, discussed the core ideas and edited the paper. TFB developed the original idea, led discussions on the topics to be studied and co-ordinated the series of papers. TFB is the guarantor for the paper. 


\section{Authors' affiliations}

J J O'Donnell, T F Beattie, Accident and Emergency Department, Royal Hospital for Sick Children, Edinburgh, UK

S C Maurice, Accident and Emergency Department, Wythenshawe Hospital, Manchester, UK

\section{REFERENCES}

1 Schecter NL. The undertreatment of pain in children: an overview. Pediatr Clin N Am 1989; 36:781-94.

2 Ball AJ, Ferguson S. Analgesia and analgesic drugs in paediatrics. $\mathrm{Br} J$ Hosp Med 1996;55:586-90.

3 Rice L. Pain management in children. Can J Anaes 1996;43:155-8.

4 Hauswald $M$, Anison $C$. Prescribing analgesics: the effect of patient age and physician speciality. Pediat Emerg Care 1997;13:262-3.

5 Visitainer MA, Wolfer JA. Psychological preparation for surgical pediatric patients: the effect on children's and parent's stress responses and adjustment. Pediatrics 1975;56:187-202.

6 Royal College of Paediatrics and Child Health. Accident and emergency services for children. London: Royal College of Paediatrics and Child Health, 1999

7 Standley JM, Hanser SB. Music therapy research and applications in pediatric oncology treatment. J Pediatr Oncol Nurs 1995;12:3-8

8 Heptinstall E. Healing the hidden hurt: the emotional effects of children's accidents. The Journal of the National Association of Hospital Play Staff $1996 ; 19: 7-19$.
9 Ross D M, Ross S A, The importance of type of question, psychological climate and subject set in interviewing children about pain. Pain 1984;19:71-9.

10 Algren JT, Algren CL. Sedation and analgesia for minor pediatric procedures. Pediatr Emerg Care 1996;12;435-41.

11 Jonas D, Day A, Binns F. Management of paediatric pain 1: non-drug approaches. Nurse Prescriber/Community Nurse 1998;March: 44-5.

12 Douthit JL. Psychosocial assessment and management of pediatric pain. J Emerg Nursing 1990:16:168-70

13 McCaffery M. Nursing approaches to non-pharmacological pain control. Int J Nurs Stud 1990;27:1-5

14 Carter B. Child and infant pain: principles of nursing care and management. London: Chapman and Hall, 1994.

15 Doody SB, Smith C, Webb J. Non-pharmacological interventions for pain management. Crit Care Nurs Clin North Am 1991;3:69-75.

16 Royal College of Paediatrics and Child Health. Prevention and control of pain in children. London: BMU Publishing Group, 1997.

17 Ellittson J. Numerous cases of surgical operations without pain in the mesmeric state. Philadelphia: Lea and Blanchard, 1843.

18 Goldie L. Hypnosis in the casualty department. BM 1956:2:1340-2.

19 Shevlin B. Emergency hypnosis. Emergency Nurse 1996;4:4-5.

20 Mayer DJ, Price DD, Raffi A. Antagonism and acupuncture analgesia in man by the narcotic antagonist naloxone. Brain Res 1976;121:368-77.

21 O'Donnell J, Ferguson LP, Beattie TF. The use of analgesia in the paediatric accident and emergency department (in press). 